\title{
SISTEM DISTRIBUSI PENJUALAN TELUR AYAM BERBASIS ANDROID MENGGUNAKAN METODE ALGORITMA DIJKSTRA
}

\author{
Agung Priyo Utomo', Muhammad Priyono Tri S.² \\ Program Studi Teknik Informatika, Universitas Kanjuruhan Malang ${ }^{1,2}$ \\ gungpriyo@gmail.com ${ }^{1}$, m.priyono.ts@unikama.ac.id ${ }^{2}$
}

\begin{abstract}
Abstrak. Perkembangan dunia bisnis yang semakin canggih sangat berpengaruh terhadap masyarakat. Contohnya perkembangan dunia teknologi informasi yang berkaitan dengan dunia usaha dan bisnis. Manfaat berkembangnya teknologi informasi ini sangat berpengaruh terhadap masyarakat, dengan adanya internet masyarakat dapat berkomunikasi dengan banyak orang hingga belahan dunia. Saat ini dunia usaha sudah menggunakan teknologi Electronic Commerce (E-Commerce). Di dunia usaha, pasar elektronik yang berbentuk aplikasi android sudah menjadi syarat utama demi berkembangnya usaha yang kita buat manfaat dari e-commerce untuk usaha juga banyak. Kecamatan Tumpang adalah sebuah daerah yang terletak di Kabupaten Malang. Di daerah tersebut mayoritas masyarakatnya banyak yang berkerja sebagai karyawan disebuah peternakan telur ayam. Salah satunya peternakan yang berada di Desa Jeru Dusun Tumpang Kecamatan Tumpang Kabupaten Malang. Dalam sistem penjualannya masih manual, bisa disebut proses penjualannya masih belum menggunakan internet atau online. Dengan demikian jangkauan antara penjual dan pembeli masih sekitar Kecamatan Tumpang saja.
\end{abstract}

Kata Kunci: Distribusi Telur, Android Studio, Java, Internet, E-Commerce.

\section{PENDAHULUAN}

Dunia bisnis yang berkembang semakin canggih sangat berpengaruh terhadap masyarakat. Contohnya perkembangan dunia teknologi smartphone android yang bisa kita manfaatkan untuk berbisnis yaitu sering disebut e-commerce. Di dunia bisnis, e-commerce berbasis aplikasi android sudah menjadi Di dunia usaha, e-commerce yang berbentuk aplikasi android sudah menjadi syarat utama demi berkembangnya usaha yang kita buat manfaat dari $e$ commerce untuk usaha juga banyak. Untuk konsumen dan pengusaha tinggal pesan produk yang diinginkan dan untuk pengusaha tinggal menawarkan produknya tidak secara manual cukup memanfaatkan teknologi e-commerce seperti pengusaha telur ayam akan lebih efisien dalam memasarkan produknya tanpa harus keliling dari pasar ke pasar.

Kecamatan Tumpang adalah sebuah daerah yang terletak di Kabupaten Malang. Di daerah tersebut mayoritas masyarakatnya banyak yang berkerja sebagai karyawan disebuah peternakan telur ayam. Salah satunya peternakan yang bernama "Mirwan Jaya" berada di Desa Jeru Dusun Tumpang Kecamatan Tumpang Kabupaten Malang. Dalam sistem penjualannya masih manual, bisa disebut proses penjualannya masih belum menggunakan smartphone android atau online. Dengan demikian jangkauan antara penjual dan pembeli masih sekitar Kecamatan Tumpang saja.

Dengan adanya permasalahan tersebut saya ingin membuat sebuah aplikasi untuk membantu pengusaha dalam memasarkan produknya. Sehingga pengusaha dapat mengurangi resiko kerugian, dimana terjadinya kecurangan pada tengkulak. Selain itu konsumen bisa lebih mudah dalam pemesanan produk(telur ayam) tanpa harus datang langsung ke peternak telur ayam. 


\section{METODE PENELITIAN}

- Bagan Program

Pembuatan bagan program yaitu untuk merancang alur dari program yang akan dibuat agar mudah dimengerti. Dalam pembuatan sistem distribusi telur ayam ini penulis menggunakan bagan program campuran. Berikut adalah gambar struktur navigasi sistem :
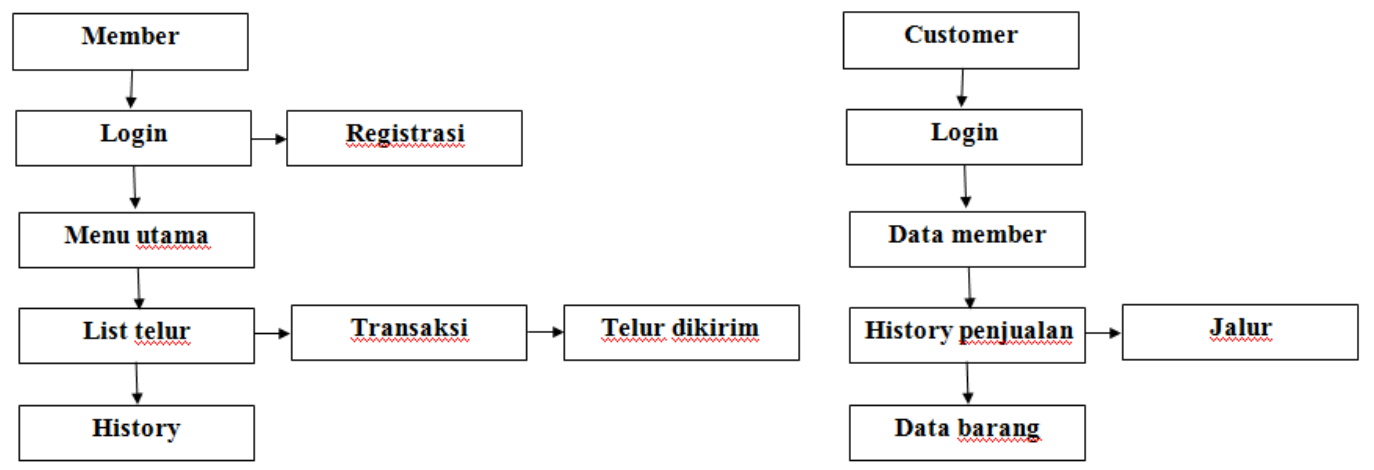

Gambar .1 Struktur navigasi system

- Use Case Diagram

Diagram ini menjelaskan cara kerja program diantaranya interaksi user dengan admin terhadap program yang akan dibuat. Pada diagram ini menjelaskan bagaimana alur sistem berjalan.

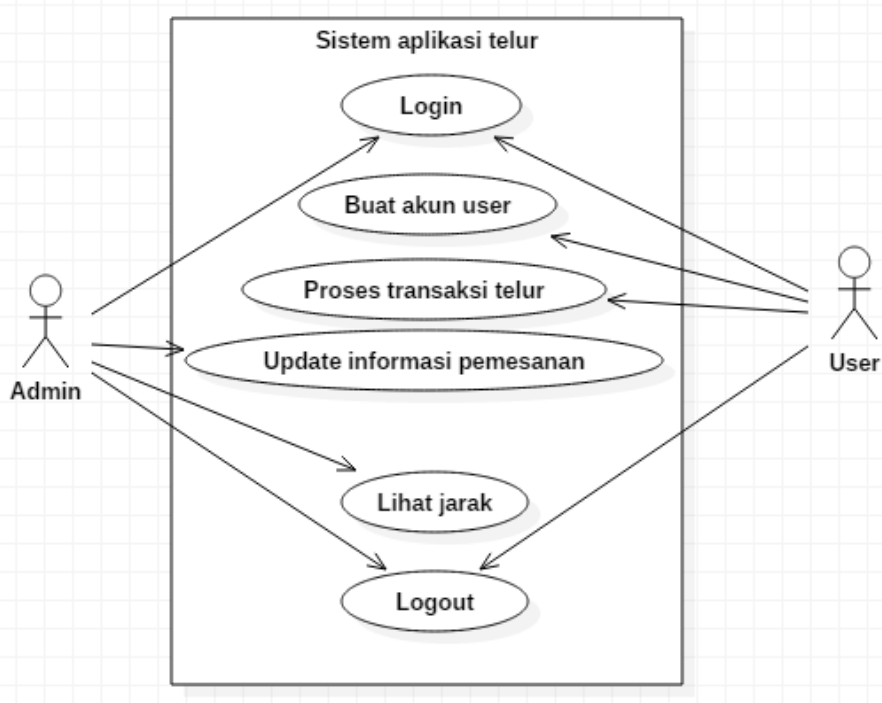

Gambar .2 Use Case Diagram Program

- Entity Relationship Diagram (ERD)

Entity Relationship Diagram (ERD) merupakan bagan awal untuk pembuatan program aplikasi dengan alurnya. 


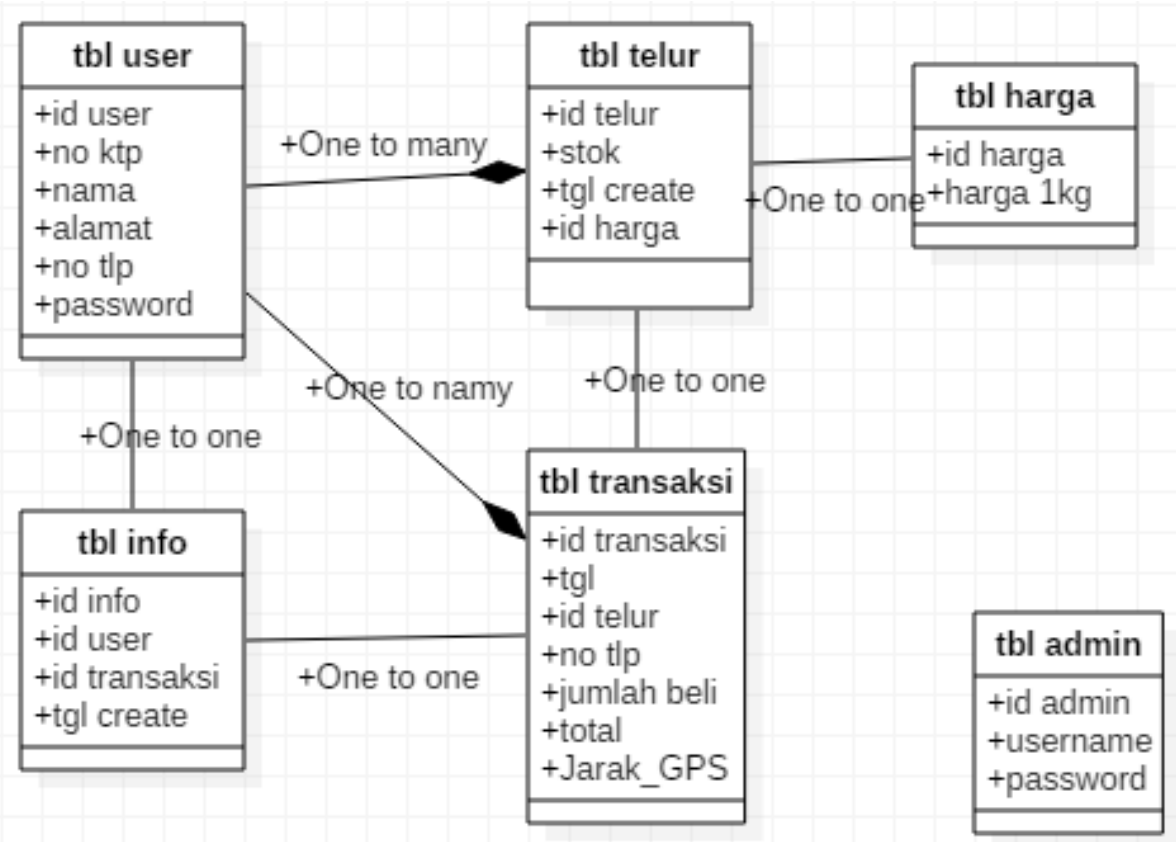

Gambar .3 Entity Relationship Diagram (ERD)

- Class Diagram

Class diagram yaitu struktur gambar bagan dari program yang akan kita buat. Bagan ini menjelaskan alur koneksi antar user dan admin. Berikut contoh bagan yang akan kita buat :

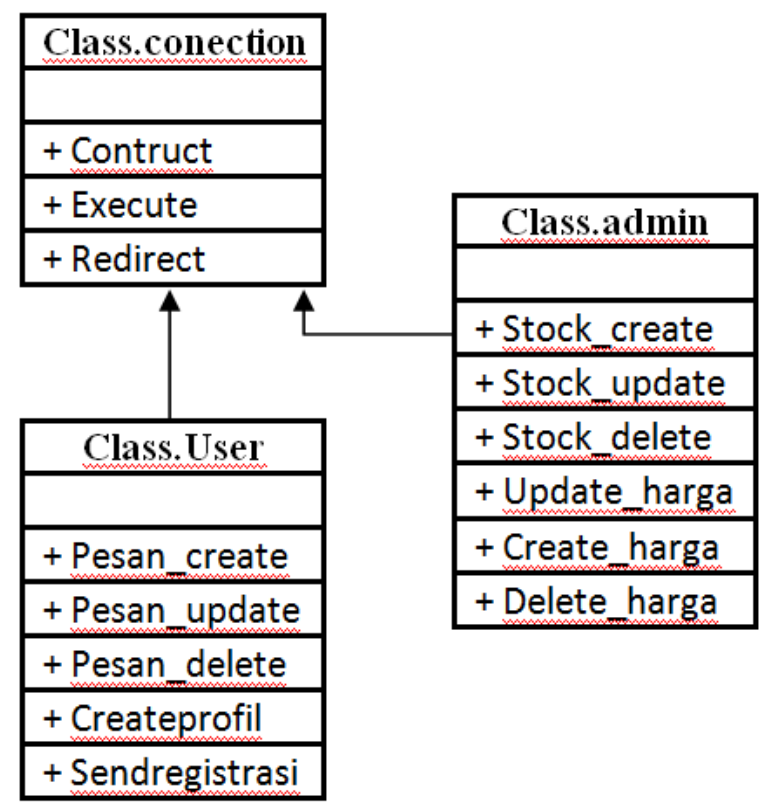

Gambar .4 Class diagram

- Desain Interface

Untuk membuat aplikasi android agar terlihat menarik, dan mudah dioperasikan oleh pengguna maka kita perlu membuat sebuah desain antarmuka (interface) dari program tersebut. Desain antarmuka bertujuan agar pengguna tidak kesulitan dalam pengoprasian program yang akan di buat. Desain interface yaitu gambaran suatu program 
yang berisikan seperti gambar, teks, dan navigasi. Berikut contoh desain interface yang telah dirancang :

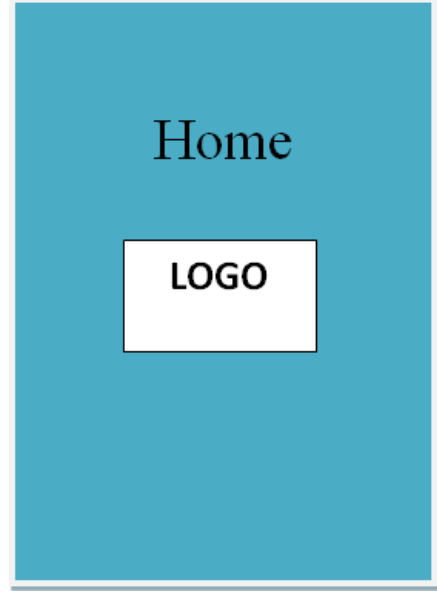
Gambar .5 Halaman utama aplikasi

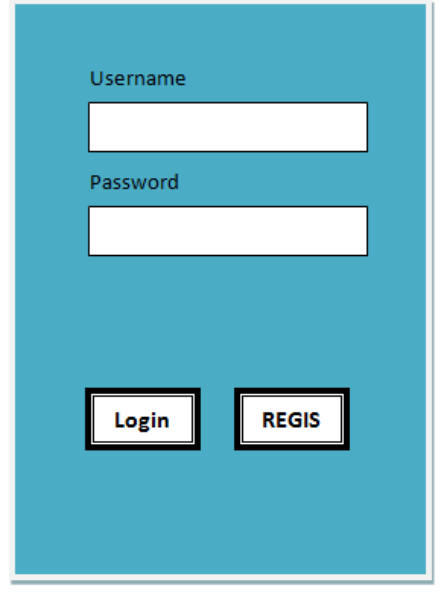
Gambar .6 Halaman login admin

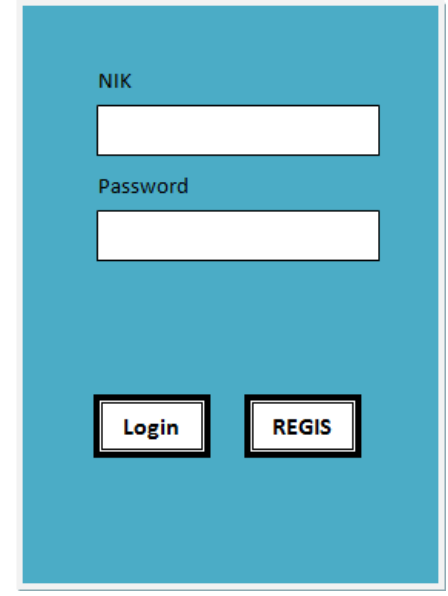

\section{Gambar .7 Halaman login user}

\section{HASIL DAN PEMBAHASAN}

Dari hasil penelitian dan perancangan aplikasi yang suadah dilakukan mulai dari tahap penelitian dan perancangan aplikasi distributor telur ayam berbasis android, menggunakan sebuah perangkat computer. Dengan dilakukan implementasi terhadap aplikasi ini dengan cara pengujian aplikasi yang akan dibuat. Berikut contoh hasil aplikasi yang sudah dirancang :

- Home admin dan member

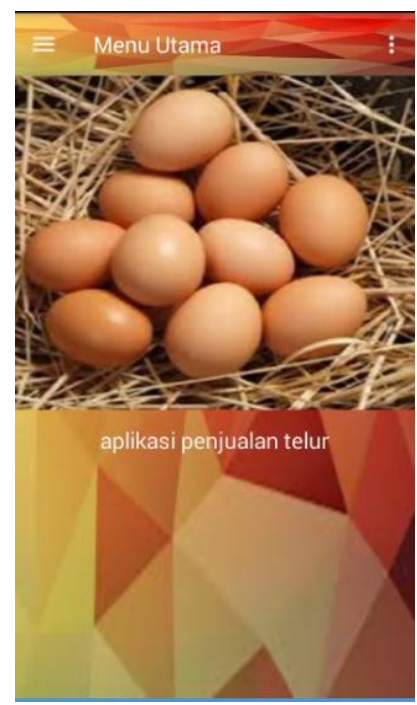

\section{Gambar .8 Home admin dan member}

Dapat dilihat pada gambar .8 diatas adalah tampilan home admin dan member. Pada tampilan tersebut terdapat halam utama dari aplikasi distributor telur ayam. Yang dimana menu ini adalah halam utama dari aplikasi ini. Dibawah ini adalah source code dari tampilan diatas. 


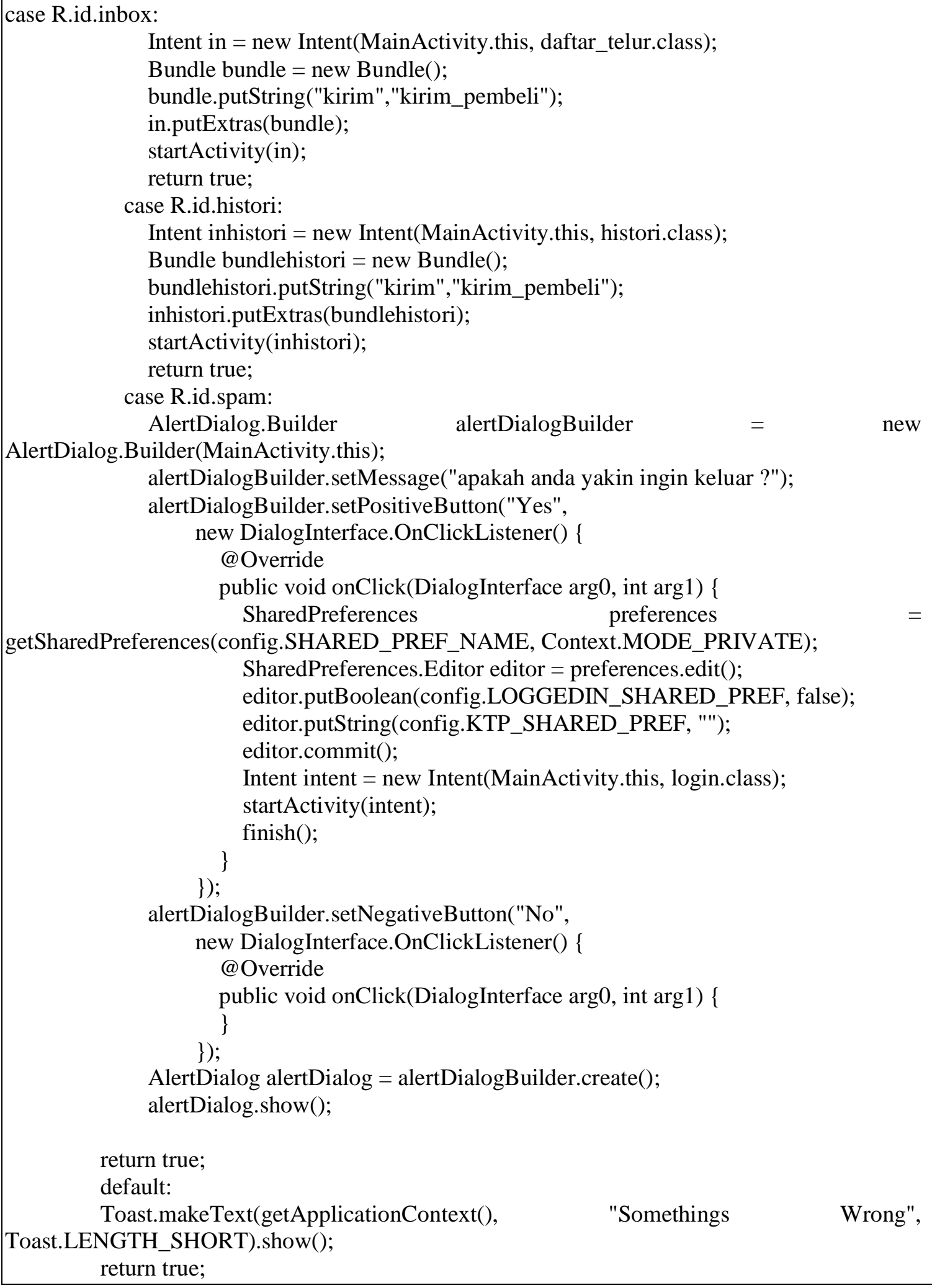




\section{Jurnal Terapan Sains \& Teknologi}

Fakultas Sains dan Teknologi - Universitas Kanjuruhan Malang
E-ISSN: 2721-6209

Vol. 2, No. 1, 2020

- Tampilan Login Admin Dan Member

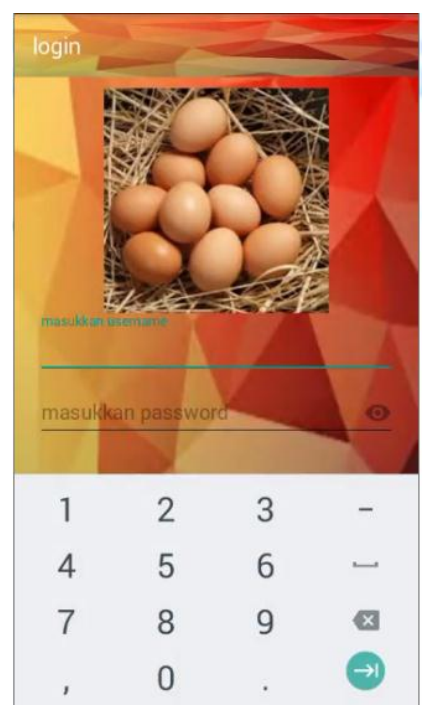

\section{Gambar.9 login admin dan member}

Dapat dilihat pada gambar .7 diatas adalah tampilan menu login admin dan member. Pada tampilan tersebut terdapat dua kolom. Yang pertama merupakan kolom username dan kolom kedua adalah kolom password. Dibawah ini adalah source code dari tampilan diatas.

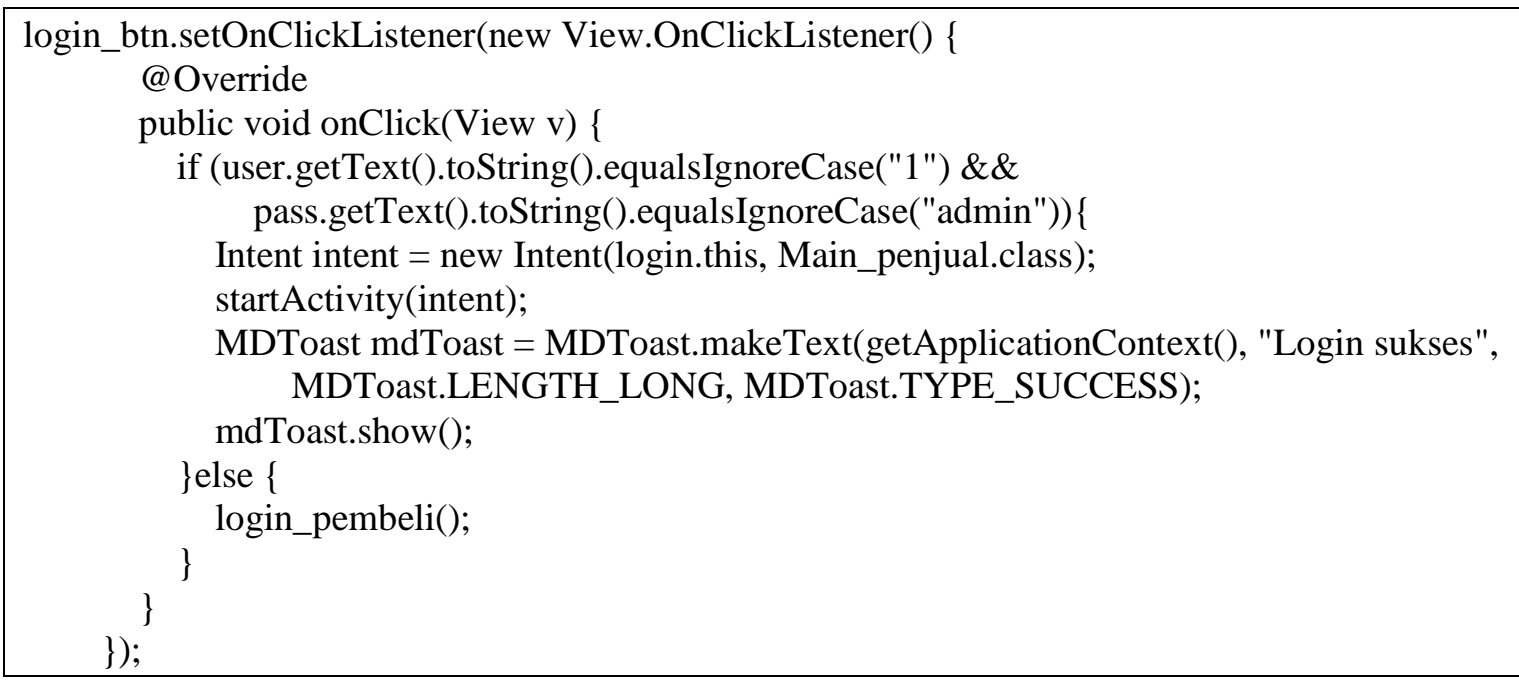

\section{PENUTUP}

Dengan dilakukan implementasi terhadap aplikasi ini dengan cara pengujian. Dengan hasil yang didapat dari penelitian dan pengujian program ini terdapat kesimpulan dari pembuatan aplikasi agar dapat digunakan dalam implementasi pembuatan aplikasi. Berikut beberapa kesimpulan dan saran dari hasil penelitian dan pembuatan program :

- Kesimpulan

Beberapa kesimpulan dari hasil pengujian ini adalah:

1. Dari pengujian aplikasi pendistribusian telur kepada masyarakat Tumpang dapat di simpulkan bahwasanya aplikasi sangat mudah di gunakan dalam pemesanan telur ayam. 
2. Dengan adanya aplikasi pendistribusian ini penjualan dapat dengan mudah melihat history pembelian dan dapat langsung mengantarkannya tanpa kebingungan.

- Saran

Untuk perkembangan program yang sudah dibuat, maka ada beberapa saran untuk mengembangkan program yang sudah ada :

1. Diharapkan dapat menggunakan metode lain sebagai perbandingan dan dapat menentukan jarak dalam pengiriman telur ayam kepada customer.

2. Perlu adanya penambahan fitur dan desain yang diperlukan.

3. Diharapkan aplikasi ini mengurangi resiko keterlambatan dalam pendistribusian telur ayam kepada customer.

\section{DAFTAR PUSTAKA}

Muslihudin, M. Analisis dan Perancangan Sistem Informasi Menggunakan Model Terstruktur dan UML. Penerbit CV. ANDI OFFSET. Yogyakarta. 2016.

Saladin, Djaslin. Unsur-Unsur Inti Pemasaran dan Manajemen Pemasaran. Penerbit Mandal Maju. Bandung. 1996.

SholeculAzis. Sekali Baca Langsung Inget: Mengupas Lengkap All About Android. Penerbit Kuncikom. Jakarta. 2012.

Suastha, Basu. Saluran Pemasaran, edisi pertama. Penerbit BPFE: Yogyakarta. 1999.

Svennerberg., G. Beginning Google Maps API 3. United States Of America. 2010. 